\title{
Editorial
}

Respirition

Respiration 2005;72:129-131

DOI: $10.1159 / 000084041$

\section{It Is Time for This 'ROSE' to Flower}

\author{
Stefano Gasparini \\ Pulmonary Diseases Unit, Department of Respiratory and Allergic Diseases, Azienda Ospedali Riuniti \\ 'Umberto $1^{\circ}$ - G.M. Lancisi - G. Salesi', Ancona, Italy
}

In the last decades, needle aspiration techniques have gained ground in respiratory medicine, especially for the diagnosis and staging of lung cancer. Techniques such as percutaneous fine-needle aspiration and transbronchial needle aspiration (TBNA) have been demonstrated to be reliable sampling tools in clinical practice. Their use allows cytohistological diagnosis of malignancy and numerous benign conditions with good sensitivity and excellent specificity, avoiding more invasive surgical procedures such as mediastinoscopy, video-assisted thoracoscopic surgery or thoracotomy $[1,2]$.

One of the advantages of the cytological aspiration techniques is the possibility to immediately evaluate the material with rapid stain methods to define the adequacy of the sample and to obtain a preliminary diagnosis, if the cytopathologist is present in the diagnostic room. The presence of a cytopathologist during the needle aspiration procedures also ensures that the material will be treated and prepared in the best way. The results obtained by the immediate cytological assessment provides the operator with invaluable information on how to carry on with the procedure that can be stopped if the material is diagnostic, avoiding further and useless passes with the needle, thereby reducing time and risks. On the contrary, if the sample is not diagnostic, other needle passes can be performed by the operator who, on the basis of the information provided by the cytopathologist, could modify the technique of sampling or the point of punction. Furthermore, if required by the immediate assessment and deemed necessary by the cytopathologist, the operator could be invited to sample additional material for ancillary techniques, such as electron microscopy, immunocy- tochemistry or microbiological studies, or to repeat the sample using histology needles, if histological material is considered useful for perfecting the diagnosis.

A 'ROSE' is a flower, but it is also the acronym frequently employed to indicate Rapid On-Site Evaluation of the material obtained by needle aspiration techniques; other authors use the less romantic acronym ICA, which stands for Immediate Cytological Assessment [3].

In recent years, in an effort to improve the sensitivity and the diagnostic yield of the needle aspiration techniques, new technologies of guidance have been proposed (endobronchial ultrasound, virtual bronchoscopy, CT fluoroscopy, 3D navigation systems) [4-6], but only few papers have focused on the role of correct management, preparation and examination of the sampled material which is an essential point to achieve good results.

In 1993, analyzing data from 55 patients who underwent percutaneous fine-needle aspiration from a lung lesion suspected for cancer, Austin and Cohen [7] obtained a sensitivity of $100 \%$ in 25 cases performed with ROSE and of $80 \%$ in 30 cases where the biopsy was performed without the cytopathologist. In the same paper, the metaanalysis of the previously published data showed that the immediate cytological assessment was associated with a statistically significant increase in diagnostic accuracy compared with the procedures performed when a cytopathologist was not present. In 1998, in a series of 207 TBNA performed on 161 patients, comparing 73 aspirates using ROSE with 134 routinely processed samples, Davenport [8] showed that the percentage of specimens containing malignant cells increased from 31 to $56 \%$ and that the inadequate TBNA decreased from 56 to $18 \%$

\section{KARGER \\ Fax +41613061234 E-Mail karger@karger.ch} www.karger.com
C 2005 S. Karger AG, Basel 0025-7931/05/0722-0129\$22.00/0

Accessible online at: www.karger.com/res
Stefano Gasparini, UO di Pneumologia

Dipartimento delle Malattie Respiratorie ed Allergiche

Azienda Ospedaliero-Universitaria Ospedali Riuniti

IT-60020 Ancona (Italy)

Tel. +39071 596 4374, Fax +39071 596 4344, E-Mail s.gasparini@fastnet.it 
when the cytopathologist was present. Likewise, in a prospective cohort study on 204 patients who underwent bronchoscopy for evaluation of lung nodules or masses and/or hilar and mediastinal lymphadenopathy, Diette et al. [9] obtained a diagnostic yield of $81 \%$ in the 81 cases performed with ROSE versus $50 \%$ in the cases without immediate cytological assessment.

Despite this evidence of diagnostic advantages, ROSE is still not a very widespread procedure, and in many institutions, the pulmonologists find several difficulties to persuade the cytopathologists to participate directly in needle aspiration activities.

There are mainly two reasons for these difficulties.

The first is due to a lack of pathologists specifically trained and dedicated to cytology in many institutions. Generally, traditional pathologists do not like to leave their offices, heading for the diagnostic rooms with a microscope. They think that this could mean a loss of time, taken away from their routine diagnostic activity. Pulmonologists should use their enthusiasm and make every effort to convince the pathologists of the diagnostic efficacy of ROSE, which could be compared in its value with the intraoperative frozen section examination activity that, on the contrary, is well spread and accepted worldwide. As underlined by Miller et al. [10] and as we have verified in our experience of more than 20 years [3], the great educational relevance of ROSE for the staff, arising from the opportunity to discuss the cases together at the time of the examination, should also be emphasized.

The second and possibly main reason why ROSE is not very widespread is that its cost effectiveness has not yet been demonstrated. Without doubt, the extra time and effort of the cytopathologist is a cost that should be considered and adequately reimbursed. The inadequate economical consideration does not encourage the cytopathologists to participate on site at the diagnostic procedures.

In this issue of Respiration, the paper of Diacon et al. [11] does not only focus on the diagnostic utility of ROSE during bronchoscopy using TBNA, but also on the economical aspects of the immediate cytological examination, with an accurate and detailed analysis of the costs of the material and the work of all the operators involved in the procedure, including physicians, nurses, cytology technicians and administrative staff. The costs have been calculated for bronchoscopies performed with ROSE and for an alternative scenario for sampling without ROSE. The results show that all the staff save time with ROSE, except for the cytopathologist who on average spends 17 min more per patient. However, even considering the rel- atively high salary of the cytopathologist, saving on consumable tools and time of the other operators allowed ROSE to save 24.8 rand (the currency of South Africa, where the study was performed) per patient. These data led the authors to conclude that ROSE is not only highly useful in increasing the diagnostic value of the TBNA procedures, but also cost effective.

As underlined by the same authors in the discussion, this conclusion is not universally generalizable and should be verified in other countries and other institutions, taking into account the different organizations of the various hospitals and the different costs that material and salaries could have. Economic analysis such as that made by Diacon et al. [11] should be encouraged, because if the cost effectiveness of ROSE will be universally confirmed, every effort will have to be made to diffuse this practice and to stimulate the different health care systems and hospital administrations to invest resources in this kind of diagnostic approach.

I hope that in the future the basic knowledge of cytopathology will be inserted in the training program of pulmonologists and will become part of their culture and qualification. Thus, the presence of a cytopathologist may no longer be necessary to perform ROSE. The pulmonologist could carry out the procedure by himself, further reducing the cost. In many cases, it could be enough to have a preliminary evaluation, demonstrating whether neoplastic cells are present in the specimen or not. Of course, the final diagnosis should remain the task of the pathologist, and nothing would be taken away from his competence and responsibility. It is incomprehensible why the pulmonologist should be able to read and interpret a CT scan, when he cannot evaluate, at least preliminarily, a cytological slide. Pulmonologists who are able to perform ROSE by themselves already exist [12], and they receive a lot of professional gratification from their practice.

At the end of this comment, let me talk about another reason that could have stimulated the enthusiasm of Diacon et al. [11] for ROSE. At the last ERS meeting in Glasgow, I had the chance to chair a session where a poster communication on ROSE was displayed by these authors. The picture showed a cytopathologist performing an immediate cytological evaluation on a microscope. Being used to a cytopathologist with a moustache, it was surprising for me to see that a wonderful, blonde woman was sitting at the microscope. ROSE is a romantic acronym: if you are lucky to have a nice woman as a cytopathologist, you could have one more reason to hope that this ROSE flowers. 


\section{References}

1 Dasgupta A, Mehta AC, Wang KP: Transbronchial needle aspiration. Semin Respir Crit Care Med 1997;18:571-581.

2 Mazzone P, Jain P, Arroliga AC, Matthay RA: Bronchoscopy and needle biopsy techniques for diagnosis and staging of lung cancer. Clin Chest Med 2002;23:137-158.

3 Gasparini S, Ferretti M, Secchi EB, Baldelli S, Zuccatosta L, Gusella P: Integration of transbronchial and percutaneous approach in the diagnosis of peripheral pulmonary nodules or masses. Experience with 1027 consecutive cases. Chest 1995;108:131-137.

4 Herth F, Becker HD, Ernst A: Conventional vs endobronchial ultrasound-guided transbronchial needle aspiration: A randomized trial. Chest 2004; 125:322-325.
5 White CS: Transbronchial needle aspiration: Guidance with CT fluoroscopy. Chest 2000; 118:1630-1638.

6 Becker HD: Bronchoscopy. Year 2001 and beyond. Clin Chest Med 2001;22: 225-239.

7 Austin JHM, Cohen MB: Value of having a cytopathologist present during percutaneous fine-needle aspiration biopsy of lung: Report of 55 cancer patients and metaanalysis of the literature. AJR Am J Roentgenol 1993;160:175177.

8 Davenport RD: Rapid on-site evaluation of transbronchial aspirates. Chest 1998;98:5961.

9 Diette GB, White P Jr, Terry P, Jenckes M, Rosenthal D, Rubin HR: Utility of on-site cytopathology assessment for bronchoscopic evaluation of lung masses and adenopathy. Chest 2000;117:1186-1190.
10 Miller DA, Carrasco CH, Katz RL, Cramer FM, Wallace S, Charnsangavej C: Fine needle aspiration biopsy: The role of immediate cytologic assessment. AJR Am J Roentgenol 1986; 147:155-158.

11 Diacon AH, Schuurmans MM, Theron J, Louw M, Wright CA, Brundyn K, Bolliger CT: Utility of rapid on-site evaluation of transbronchial needle aspirates. Respiration 2005; 72:182-188.

12 Marcianò G, Marino M: Broncologia. Endoscopia e Citologia. Milano, UTET Ed, 1993. 